\title{
INTRASPECIFIC AGGREGATION ALTERS COMPETITIVE INTERACTIONS IN EXPERIMENTAL PLANT COMMUNITIES
}

\author{
Peter Stoll ${ }^{1,3}$ AND DANiel Prati ${ }^{2}$ \\ ${ }^{1}$ Geobotanisches Institut, Universität Bern, Altenbergrain 21, CH-3013 Bern, Switzerland \\ ${ }^{2} U F Z$ Centre for Environmental Research Leipzig-Halle Ltd., Department of Community Ecology, \\ Theodor-Lieser-Strasse 4, D-06120 Halle/Saale, Germany
}

\begin{abstract}
We tested the prediction from spatial competition models that intraspecific aggregation may promote coexistence and thus maintain biodiversity with experimental communities of four annual species. Monocultures, three-species mixtures, and the fourspecies mixture were sown at two densities and with either random or intraspecifically aggregated distributions. There was a hierarchy of competitive abilities among the four species. The weaker competitors showed higher aboveground biomass in the aggregated distribution compared to the random distribution, especially at high density. In one species, intraspecific aggregation resulted in an $86 \%$ increase in the number of flowering individuals and a $171 \%$ increase in the reproductive biomass at high density. The competitively superior species had a lower biomass in the aggregated distribution than in the random distribution at high density. The data support the hypothesis that the spatial distribution of plants profoundly affects competition in such a way that weaker competitors increase their fitness while stronger competitors are suppressed when grown in the neighborhood of conspecifics. This implies that the spatial arrangement of plants in a community can be an important determinant of species coexistence and biodiversity.
\end{abstract}

Key words: biodiversity; Capsella bursa-pastoris; Cardamine hirsuta; coexistence; competitive exclusion; intra- vs. interspecific competition; local aggregation; Poa annua; spatial theory; Stellaria media.

\section{INTRODUCTION}

In natural communities most species are not randomly distributed, but often locally aggregated on one or several spatial scales. In plants local or intraspecific aggregation is generated by limited seed dispersal, clonal growth and patchy environments. As a consequence of the sessile life-style of plants, individuals interfere mainly with close neighbors, and therefore the details of the local distribution of plants within communities are of fundamental importance (Pacala 1997). There is a large body of theoretical models that highlights the importance of spatial patterns in ecology but also urges the experimental validation of "spatial theory" (Tilman and Kareiva 1997, Dieckmann et al. 2000). Similarly, although there is a wealth of empirical studies on competition in plants and the various factors affecting it, very little is actually known about how the spatial structure of communities changes inter- and intraspecific competition (Goldberg and Barton 1992, Gurevitch et al. 1992). It is the aim of this report to start filling the gap between theory and practice and to present direct experimental evidence that intraspecific aggregation (= interspecific segregation) affects plant competition profoundly.

"Spatial theory", i.e., models that explicitly include space, generally show that the spatial structure of com-

\footnotetext{
${ }^{3}$ E-mail: stoll@sgi.unibe.ch
}

munities can influence many ecological phenomena such as the temporal stability of population dynamics, biological invasions, coexistence and the maintenance of biodiversity, ecosystem function, and community structure (Horn and MacArthur 1972, Weiner and Conte 1981, Shmida and Ellner 1984, Czárán and Bartha 1992, Silvertown et al. 1992, Durrett and Levin 1994, Hassell et al. 1994, Tilman 1994, Pacala and Deutschman 1995, Wilson and Nisbet 1997, Bolker and Pacala 1999). Intraspecific aggregation changes the frequency of inter- vs. intraspecific encounters so that individuals interfere more often with conspecifics as would be expected from their overall abundance. Competitively superior species become suppressed, which in turn prevents or at least retards the elimination of competitively inferior species. Altering the speed of competitive exclusion can tip the balance from competitive exclusion to coexistence and, thus, promote species diversity (Kareiva 1990, Tilman 1994, Rees et al. 1996, Pacala 1997, Stoll and Weiner 2000). Experimental tests of competitive interactions with randomly or regularly dispersed plants can therefore give misleading results.

Despite a rich body of theory and models, there are only few empirical and even fewer experimental studies that directly address the impact of spatial patterns on plant population and community dynamics (Tilman and Kareiva 1997). Early experimental work showed that the ranking of emergence time and spatial separation 


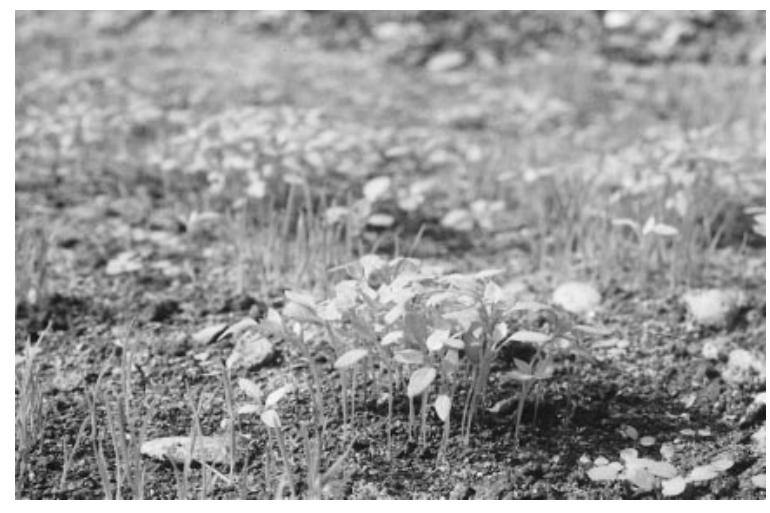

Plate. 1. Close-up photograph of seedlings in a threespecies mixture (high density, aggregated) one week after sowing with Stellaria (middle), Cardamine (lower right), and Poa. (Photograph by August Hämmerli.)

from neighbors can be very important for an individual to occupy space and exclude neighbors (Sakai 1957 [as cited in Harper 1977], Ross and Harper 1972). But only few experiments followed to test the generality of these conclusions (see Schmid and Harper [1985] and Bergelson [1990] as notable exceptions).

In this paper we studied the effect of intraspecific aggregation in a simple experimental community of four annual weed species. A test of "spatial theory" is a two-step process that requires, first, a description of whether and on which spatial scale aggregation of plants occurs, and second, how this aggregation alters the interaction between species. While field observations focus on the first step, they suffer from the inability to determine the causal relationship between intraspecific aggregation and species interaction as they lack the control of a randomly dispersed community (e.g., Rees et al. 1996). Our aim was to concentrate on the second step. Therefore, we experimentally established a community of intraspecific aggregated plants, to compare it with one of randomly dispersed plants and to elucidate the precise consequences of intraspecific aggregation on species interactions. In particular we tested the following predictions: (1) Intraspecific aggregation affects competitive interactions in such a way that competitively inferior species grow better when locally aggregated than when randomly dispersed. (2) Intraspecific aggregation should also increase the fitness of otherwise-inferior species and thus promote species diversity in the long term. (3) As the overall density of plants generally affects the intensity of competition, we ran the experiment at two densities and predicted that the effect of intraspecific aggregation is more pronounced at high density.

\section{Materials and Methods}

We investigated the effect of intraspecific aggregation and density in a garden experiment (Botanical Garden of the University of Berne [Switzerland]) with four common, co-occurring annual or biannual species with different morphology. Capsella bursa-pastoris L. and Cardamine hirsuta L. are both rosette-forming plants of the Brassicaceae with a multi-flowered erect stem up to $40 \mathrm{~cm}$ (Capsella) or $30 \mathrm{~cm}$ (Cardamine) high. The annual Poa annua L. (Poaceae) has adventitious roots at the first nodes and tillers up to $30 \mathrm{~cm}$ high. Finally, Stellaria media L. (Caryophyllaceae) is prostrate to ascending, with high adventitious rooting and a height of up to $40 \mathrm{~cm}$. We used a randomized splitplot design (Fig. 1) with spatial pattern and density as plot-level treatments (Fig. 1a) and combinations of mixtures of species and monocultures as within-plot treatments (Fig. 1b). Plot treatments were replicated 4 times and plots were randomly assigned to the combinations of random vs. aggregated pattern and high vs. low density, yielding a total of 16 plots (arranged in 8 plots per block, see below). The main plots of 60 $\times 60 \mathrm{~cm}$ were subdivided into nine subplots of $20 \times$ $20 \mathrm{~cm}$, each of which contained either (1) one of the four species in monoculture, or (2) one of the four possible three-species mixtures, or (3) the four-species mixture.

In the random pattern seeds of each species were sown over the subplots in such a way that, in the mixtures, the individuals should experience inter- and intraspecific encounters at the same frequency. In the aggregated sowing pattern, the subplots were further subdivided into 16 cells of $5 \times 5 \mathrm{~cm}$ (Fig. 1c), and each cell contained only one of the species so that individuals experienced more intra- than interspecific encounters. The species were randomly allocated to the cells. In the four-species mixture each species occupied four cells, whereas in the three-species mixtures each species occupied five cells and one third of the sixteenth cell. At low density we sowed 10 seeds per 5 $\times 5 \mathrm{~cm}$ cell $\left(4000 \mathrm{seeds} / \mathrm{m}^{2}\right)$ whereas at high density we sowed 100 seeds per $5 \times 5 \mathrm{~cm}$ cell $(40000$ seeds/ $\mathrm{m}^{2}$ ). For the low-density treatment the 10 seeds were counted whereas for the high-density treatment $\sim 100$ seeds were weighed based on 10 samples of exactly 100 seeds. The seeds were obtained from a commercial supplier (Herbiseed, Wokingham, Berkshire, UK).

On 18 May 1999 the plots were set up in two blocks $(1 \times 10 \mathrm{~m})$ divided in an upper and lower sub-block, each containing four plots, one of each randomly assigned pattern and density treatment. Plots were separated by leaving $20 \mathrm{~cm}$ between them and from the border of the blocks. The nutrient-rich garden soil was ploughed and steam sterilized for $20 \mathrm{~min}$ at $>90^{\circ} \mathrm{C}$ to a depth of $\sim 20 \mathrm{~cm}$ to minimize natural seed germination. Larger stones were removed, and the topsoil homogenized. The seeds were sown directly on the bare soil and covered with a thin layer of sieved topsoil that was slightly pressed down to prevent them from being washed away. The first block was sown on 23-24 May and the second on 4-5 June. The seedlings appeared after 1-3 d, first Capsella and Stellaria, then Poa, and then, with up to 1-wk delay, Cardamine (see Plate 1). 
a)

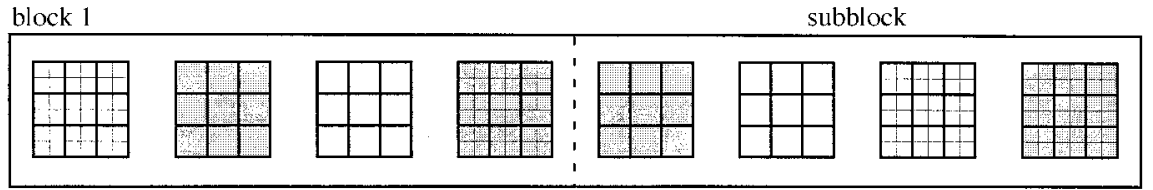

block 2

b)

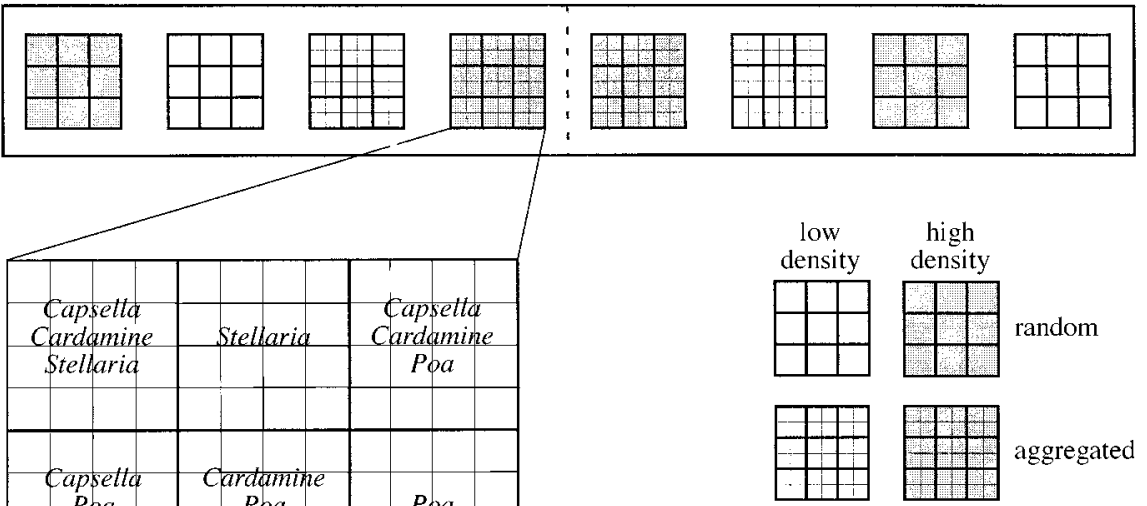

c)

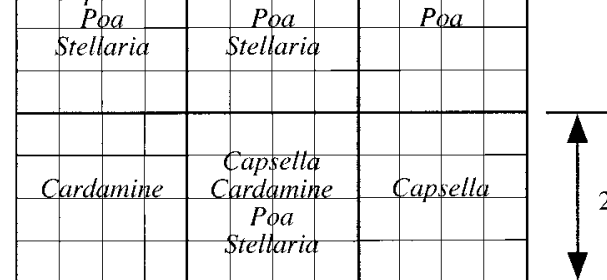

$20 \mathrm{~cm}$

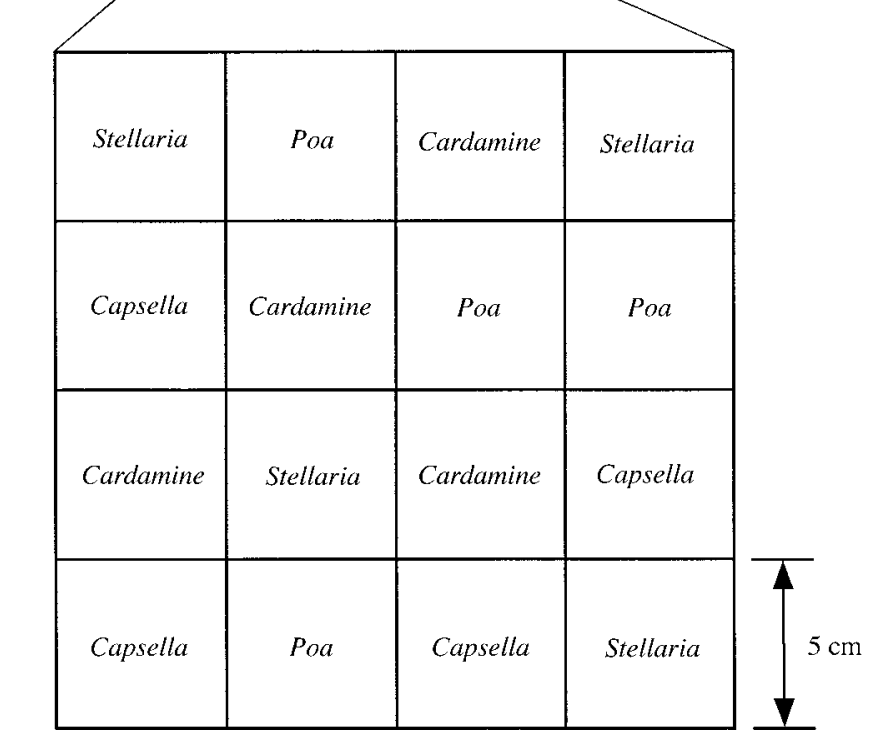

FIG. 1. The experimental design. (a) The two blocks, which were split into subblocks each containing four plots with either high or low sowing density and random or aggregated distribution yielding $n=4$ replicates per treatment and monoculture, three-species, or four-species combination. (b) Nine subplots with the four monocultures, the four three-species mixtures, and the four-species mixture. (c) An example of the intraspecifically aggregated pattern. In the random distribution, the corresponding number of seeds of all species were distributed throughout the $20 \times 20 \mathrm{~cm}$ subplot. 
TABLE 1. Results of ANOVA, showing degrees of freedom and $F$ values for the effects of pattern (random vs. intraspecific aggregation) and sowing density on various combinations of mixtures and monocultures of four (bi-) annual species.

\begin{tabular}{|c|c|c|c|c|c|}
\hline \multirow[b]{2}{*}{ Sources of variation } & \multirow[b]{2}{*}{ df } & \multicolumn{4}{|c|}{ Capsella bursa-pastoris } \\
\hline & & Total dry mass & $\begin{array}{l}\text { Reproductive } \\
\text { mass }\end{array}$ & $\begin{array}{l}\text { Total no. of } \\
\text { individuals }\end{array}$ & $\begin{array}{c}\text { No. of } \\
\text { flowering } \\
\text { individuals }\end{array}$ \\
\hline 1) Block & 1 & 2.07 & $14.48 * *$ & 2.04 & $8.68 *$ \\
\hline 2) Subblock & 2 & 2.61 & 3.21 & 3.08 & 1.72 \\
\hline 3) Pattern, $P$ & 1 & $3.97 *)$ & $7.16^{*}$ & 0.00 & 1.40 \\
\hline 4) Density, D & 1 & 0.85 & $4.40^{(*)}$ & $273.99 * * *$ & $17.64 * *$ \\
\hline 5) $P \times D$ & 1 & $8.16 *$ & $17.03 * *$ & 0.66 & $15.60 * *$ \\
\hline 6) Plot level & 9 & 0.60 & 0.82 & 1.89 & 0.95 \\
\hline 7) Combination, $\mathrm{C}$ & 4 & $11.80 * * *$ & $8.53 * * *$ & $2.08^{(*)}$ & $5.31 * * *$ \\
\hline a) Mono vs. Mix, $\mathrm{MM} \dagger$ & 1 & $15.37 * * *$ & $9.27 * *$ & $\ldots$ & 1.84 \\
\hline b) 3 vs. 4 species, $\mathrm{T} \dagger$ & 1 & 0.27 & 0.42 & $\ldots$ & 2.04 \\
\hline c) Among 3 species, $\mathrm{A} \dagger$ & 2 & $15.78 * * *$ & $12.21 * *$ & $\ldots$ & $8.68 * *$ \\
\hline 8) $\mathrm{C} \times \mathrm{P}$ & 4 & 1.32 & 1.58 & 0.28 & 0.77 \\
\hline a) $\mathrm{MM} \times \mathrm{P}$ & 1 & $\ldots$ & $\ldots$ & $\ldots$ & $\ldots$ \\
\hline b) $\mathrm{T} \times \mathrm{P}$ & 1 & $\ldots$ & $\ldots$ & $\ldots$ & $\ldots$ \\
\hline c) $\mathrm{A} \times \mathrm{P}$ & 2 & $\ldots$ & $\ldots$ & $\ldots$ & $\ldots$ \\
\hline 9) $C \times D$ & 4 & 1.84 & 1.91 & 1.67 & $3.15 *$ \\
\hline a) $\mathrm{MM} \times \mathrm{D}$ & 1 & $\ldots$ & $\ldots$ & $\ldots$ & 1.96 \\
\hline b) $\mathrm{T} \times \mathrm{D}$ & 1 & $\ldots$ & $\ldots$ & $\ldots$ & $6.71 *$ \\
\hline c) $\mathrm{A} \times \mathrm{D}$ & 2 & $\ldots$ & $\ldots$ & $\ldots$ & 1.96 \\
\hline 10) $C \times P \times D$ & 4 & 1.04 & 0.41 & 0.79 & 0.41 \\
\hline 11) Residual MS & 48 & 0.5372 & $0.5249 \$$ & 0.1315 & $0.3109 \neq$ \\
\hline
\end{tabular}

Notes: The $F$ ratios for the plot-level treatments (pattern, density, and interaction) are based on the plot-level residual mean squares (not shown). All data were log-transformed prior to analyses.

$* P<0.1, * P<0.05, * * P<0.01, * * * P<0.001$.

$\dagger$ Linear contrasts to separate the combination term into the difference between monoculture and mixtures (MM), difference between the three- and four-species mixtures (T), and the difference among the three-species mixtures (A).

$\ddagger$ Residual $\mathrm{df}=47$ due to missing values.

During the first weeks, seedlings and young plants were covered by a shadecloth during periods of full sunlight and watered daily.

Six weeks after the onset of the experiment in each block, plants were harvested aboveground. We counted the number of flowering and non-flowering individuals of Cardamine and Capsella, separated the flowering plants into vegetative and reproductive parts, dried them at $80^{\circ} \mathrm{C}$, and weighed them. For Poa and Stellaria we could not determine individuals due to excessive clonal growth and adventitious rooting and solely measured the dry mass. Only very few shoots of Poa flowered, whereas almost all shoots of Stellaria had at least one flower.

Data were analyzed with multifactorial analysis of variance (ANOVA) for a split-plot design. The main effects (pattern, density) and their interaction were tested against the plot-level residual mean squares. When the effect of the combination was significant, we used linear contrasts to separate them into (1) the difference between monoculture and mixtures, (2) difference between the three- and four-species mixtures, and (3) the difference among the three-species mixtures. Data were calculated as grams per square meter or number of individuals per square meter and log-transformed to achieve normality of the residuals and homogeneity of variances. Backtransformed means and standard errors from the analyses are presented throughout. All anal- yses were computed using the program GENSTAT 5 (Payne et al. 1987).

\section{RESULTS}

The four species differed in their overall performance over two orders of magnitude. Stellaria media reached the highest average aboveground biomass of $1114 \mathrm{~g} / \mathrm{m}^{2}$, followed by Capsella bursa-pastoris with $188.3 \mathrm{~g} / \mathrm{m}^{2}$ and Poa annua with $97.4 \mathrm{~g} / \mathrm{m}^{2}$ and by Cardamine hirsuta with an average of $11.7 \mathrm{~g} / \mathrm{m}^{2}$ showing the lowest performance. These marked differences in biomass among species led to a clear hierarchy of competitive ability (CA) which we calculated for each species as the aboveground biomass in the mixtures divided by the biomass in monocultures for each of the 16 plots. Only Stellaria showed a CA significantly larger than $1(2.16 \pm 0.109$ [mean $\pm 1 \mathrm{SE}])$, indicating that for Stellaria intraspecific competition was larger than interspecific competition. The opposite was true for the other three species, which had CAs $<1(0.802 \pm 0.127$ for Capsella, $0.600 \pm 0.048$ for Poa, and $0.309 \pm 0.055$ for Cardamine), indicating that these species suffered from growing in mixtures.

The spatial distribution of the plants significantly influenced competitive interactions among the species (Table 1, Fig. 2). The competitively intermediate species Capsella had more biomass in the aggregated distribution than when it was randomly distributed, but 
TABle 1. Extended.

\begin{tabular}{|c|c|c|c|}
\hline \multicolumn{2}{|c|}{ Cardamine hirsuta } & \multirow{2}{*}{$\begin{array}{c}\text { Poa anпua } \\
\begin{array}{c}\text { Total dry } \\
\text { mass }\end{array}\end{array}$} & \multirow{2}{*}{$\begin{array}{c}\begin{array}{c}\text { Stellaria } \\
\text { media }\end{array} \\
\begin{array}{c}\text { Total dry } \\
\text { mass }\end{array}\end{array}$} \\
\hline $\begin{array}{c}\text { Total dry } \\
\text { mass }\end{array}$ & $\begin{array}{l}\text { Total no. of } \\
\text { individuals }\end{array}$ & & \\
\hline $8.27 *$ & $35.98 * * *$ & 0.29 & 0.74 \\
\hline 0.30 & 0.08 & $6.03 *$ & $4.80 *$ \\
\hline 1.63 & 0.00 & $7.11 *$ & 0.10 \\
\hline 0.10 & $67.41 * * *$ & $21.45 * * *$ & $38.88 * * *$ \\
\hline 0.17 & 0.23 & 0.46 & $9.19 *$ \\
\hline 3.60 & 0.83 & 2.41 & 3.36 \\
\hline $18.01 * * *$ & $76.32 * * *$ & $32.43 * * *$ & $38.25^{* * *}$ \\
\hline $60.57 * * *$ & $5.59 *$ & $54.56 * * *$ & $143.46 * * *$ \\
\hline 2.38 & $294.30 * * *$ & $7.75 * *$ & $9.36 * *$ \\
\hline $4.55^{*}$ & 2.69 & $33.71 * * *$ & 0.09 \\
\hline 0.65 & 0.27 & $5.23 * * *$ & $2.82 *$ \\
\hline$\ldots$ & $\ldots$ & 0.00 & 1.50 \\
\hline$\ldots$ & $\ldots$ & 3.52 & 1.62 \\
\hline$\ldots$ & $\ldots$ & $8.70 * *$ & $4.07 *$ \\
\hline $2.43^{(*)}$ & 1.21 & $2.39^{(*)}$ & $2.17^{(*)}$ \\
\hline$\ldots$ & $\ldots$ & $\ldots$ & $\ldots$ \\
\hline$\ldots$ & $\ldots$ & $\ldots$ & $\ldots$ \\
\hline$\ldots$ & $\ldots$ & $\ldots$ & $\ldots$ \\
\hline 1.73 & 0.38 & 0.26 & 0.72 \\
\hline $0.689 \ddagger$ & $1.005 \ddagger$ & 0.1127 & 0.0470 \\
\hline
\end{tabular}

only at high density as evidenced by the significant pattern $\times$ density interaction (Table 1 : row 5, Fig. 2 a). For the weakest competitor, Cardamine, there was a trend towards higher biomass in the aggregated distribution, but due to the large variation, this was not significant (Fig. 2b). For Poa, the other competitively intermediate species, we found a significant increase of dry mass from low to high density and from the random to the aggregated pattern (Table 1: rows 3 and 4) and again the effect of aggregation was more pronounced at high density (Fig. 2c). In contrast, the competitively superior species Stellaria had no pattern main effect because of a significant pattern $\times$ density interaction (Table 1: row 5), i.e., it had significantly lower biomass in the aggregated than in the random distribution at high density, but higher biomass if aggregated at low density (Fig. 2d).

Because of the highly significant differences among the species combinations (Table 1: row 7) for almost all variables and species, we calculated linear contrasts among the various combinations of mixtures (Table 1: lines $7 a-7 c)$ and graphed the results for high density (Fig. 3). This revealed that the positive effect of aggregation on the aboveground biomass in Capsella only occurred when Stellaria was present in the mixture (Fig. 3a). In addition, whereas the pattern main effect for total dry mass in Capsella was only marginally significant using all mixtures and both densities, there was a positive effect of aggregation on Capsella only in the case of high density, and in those mixtures where Stellaria was present $\left(F_{1,3}=10.96 ; P<0.05\right)$. For Cardamine there was a strong reduction from monocultures to mixtures and slightly more biomass when Stellaria was present in the mixture (Fig. 3b). For Poa,

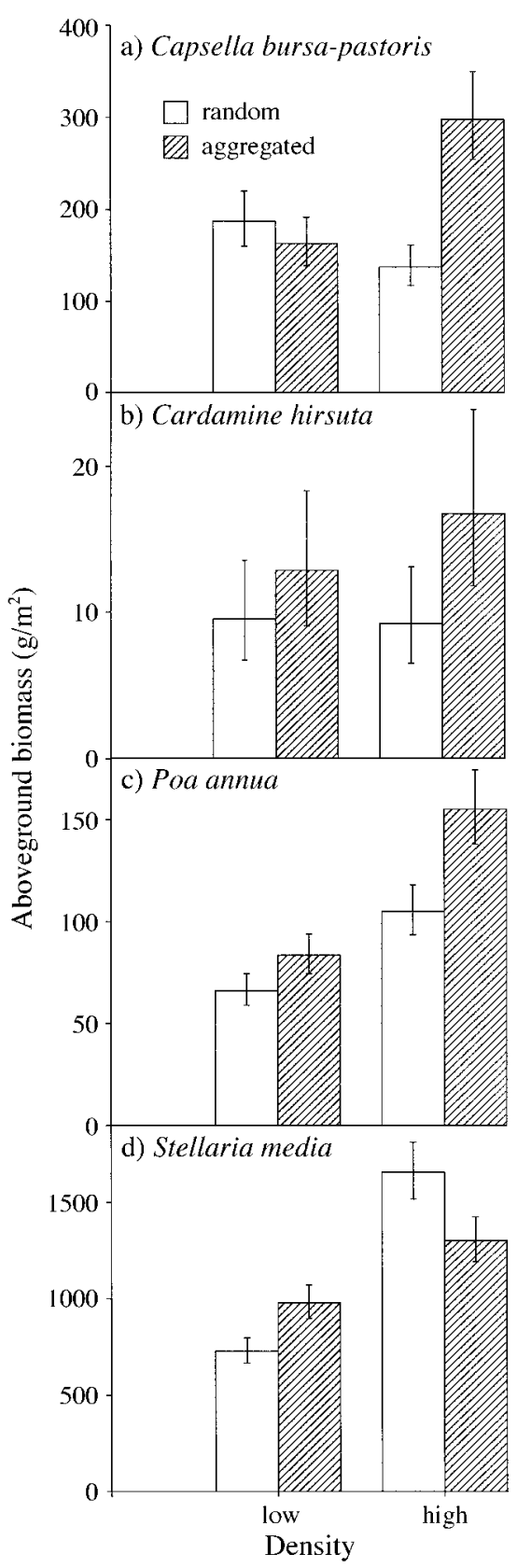

FIG. 2. The effect of intraspecific aggregation and sowing density on aboveground biomass for each of the four study species, averaged over all mixtures including monocultures. The bars represent backtransformed means \pm 1 SE from analysis of variance of log-transformed data. Note the different scaling of the $y$-axes.

the positive effect of aggregation again occurred only when Stellaria was not present in the mixtures, as indicated by a significant combination $\times$ pattern interaction (Table 1: row 8, Fig. 3c). In contrast, Stellaria responded negatively to aggregation only when Capsella was present in the mixtures (Fig. 3d). That is, dry mass of Stellaria in monoculture and the mixture with 


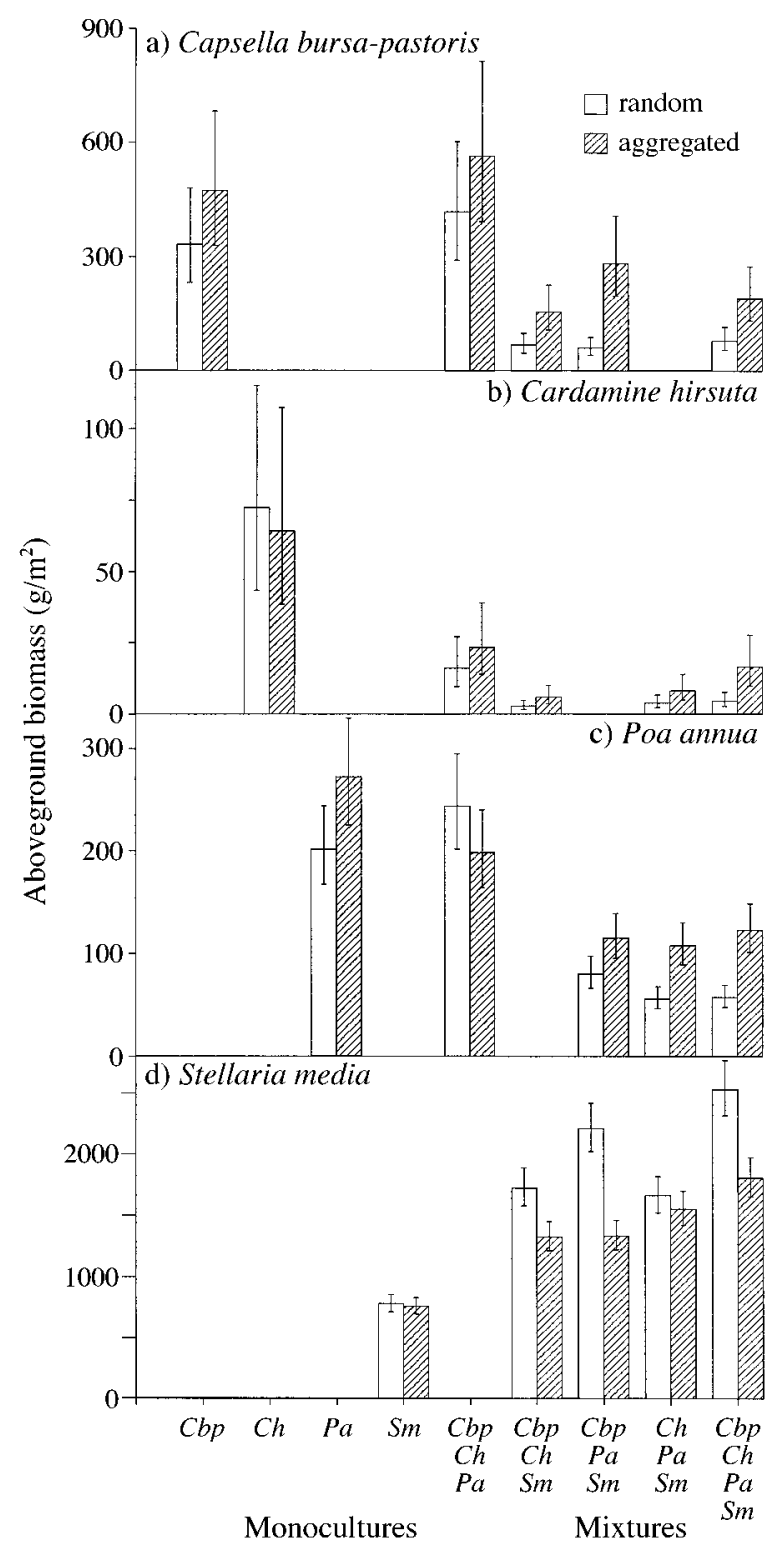

FIG. 3. The effect of intraspecific aggregation and various combinations of mixtures and monocultures in the high-density treatment ( $n=4$ replicates per pattern) on aboveground biomass for the four study species. Species abbreviations for the four monocultures, the three-species mixtures, and the four-species mixture are: $C b p=$ Capsella bursa-pastoris, $C h$ $=$ Cardamine hirsuta, $\mathrm{Pa}=$ Poa annua , and $\mathrm{Sm}=$ Stellaria media. The bars represent backtransformed means $\pm 1 \mathrm{SE}$ from analysis of variance of log-transformed data. Note the different scaling of the $y$-axes.

Poa and Cardamine was similar in both patterns but higher in the random pattern in the mixtures containing Capsella.

Note that in the monocultures we found higher biomass for Capsella and Poa in the aggregated pattern (Fig. 3a and c). Although the differences were not sig- nificant we would not expect any differences between the sowing pattern in monocultures as they differed only in the particular way of sowing (in the aggregated treatment each cell was sown individually with the appropriate number of seeds while in the random treatment the seeds were distributed throughout the subplot). However, analyses excluding the monocultures did not change qualitatively the effect of aggregation on Capsella and Poa (analyses not shown).

The spatial pattern also influenced the likelihood of flowering and allocation to reproductive tissues in Capsella bursa-pastoris (Table 1). While there was no difference in the total number of individuals due to the sowing pattern (just a trivial effect of the sowing density, Fig. 4a), we found a significant interaction in the number of flowering individuals (Table 1: row 5). At low density there were fewer flowering individuals in the aggregated than in the random pattern, but at high

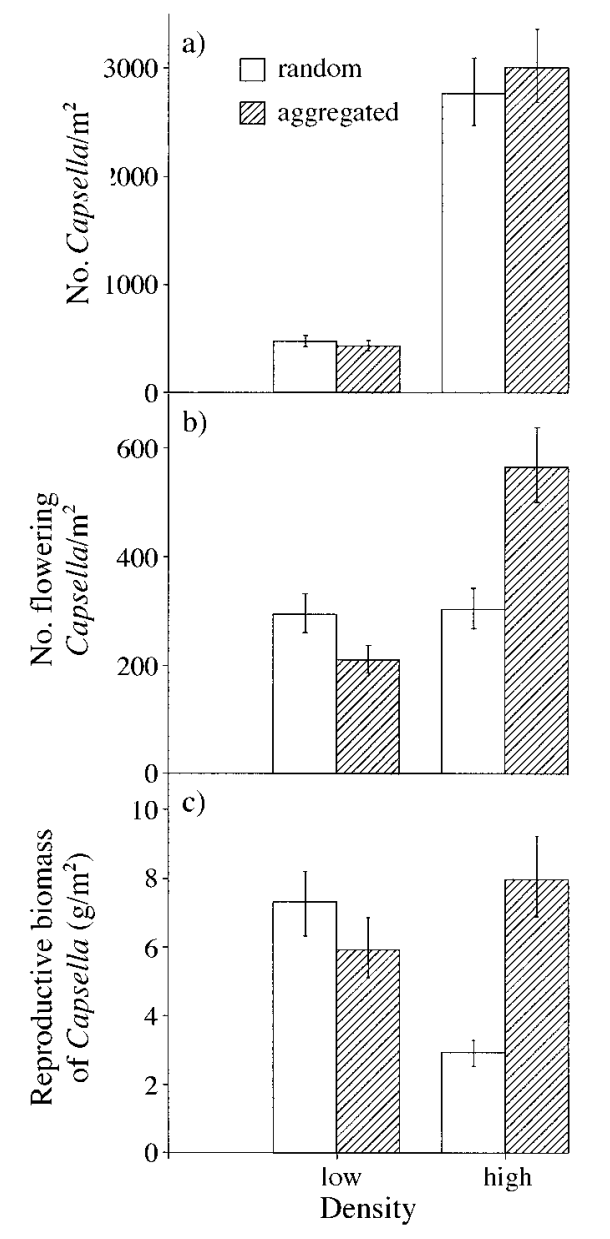

FIG. 4. The effect of intraspecific aggregation and sowing density on (a) the number of individuals, (b) the number of flowering individuals, and (c) the reproductive biomass of Capsella bursa-pastoris ( $n=4$ replicates, averaged over all mixtures including monocultures). The bars represent backtransformed means $\pm 1 \mathrm{SE}$ from analysis of variance of logtransformed data. 
density intraspecific aggregation resulted in an $86 \%$ increase in the number of flowering individuals (Fig. 4b). A similar interaction between pattern and density was found in the reproductive biomass (seeds and flowers) of Capsella. At low density the reproductive biomass did not differ between the patterns, but at high density intraspecific aggregation increased the reproductive biomass by up to $171 \%$ (Fig. 4c). In Cardamine hirsuta there was no effect of density or pattern on the reproductive biomass, probably because of the generally poor performance of this species.

\section{Discussion}

The experiment showed that spatial distribution can profoundly affect growth and reproduction of plants within an experimental community. Intraspecific aggregation decreased the performance of the superior species Stellaria, while competitively inferior species (Poa, Capsella, and in part Cardamine) profited from being surrounded by conspecifics. As predicted, this effect was more pronounced at higher densities when competition was generally more intense. To our knowledge this is one of the first pieces of experimental evidence that the spatial arrangement of plants can change the outcome of interspecific competition. This in turn can have marked effects on community structure and the maintenance of biodiversity, reinforcing the need to explicitly consider spatial effects more often than is currently done (Tilman and Kareiva 1997).

There have been few attempts to test experimentally the effect of spatial aggregation on plant competition in general. Even in agroecosystems, effects of spatial aggregation of weeds have rarely been considered (Garrett and Dixon 1998). In an experiment similar to ours, Bergelson (1990) found that the performance of Capsella bursa-pastoris and Senecio vulgaris (measured as number of seedlings in the following generation) was 4-6 times higher when grown in a patchy matrix of Poa annua than in a matrix of randomly distributed $P$. апnиа. Her experiment lasted over two generations, which shows that the pattern of distribution can influence the competitive interactions not only in the short term but also in the offspring generation. The observed effects in her experiment, however, were explained rather indirectly by litter accumulation of the matrix species (Poa) and not by changing the relative frequency of inter- and intraspecific encounters of the individuals of all species. Our experiment showed that local aggregation affects individual performance and has quite different effects depending on the species and competitive superiority.

In a long-term observational study on the dynamics of winter annuals in sand dunes, Rees et al. (1996) arrived at the similar conclusion that the spatial distribution of individuals is of fundamental importance for the weakness of interspecific interactions under field conditions. Their results stem from patterns of aggregation observed in the field, long-term monitoring of species dynamics, and extensive modeling. We regard our experimental approach using deliberately established spatial patterns and including controls of randomly mixed communities as complementary to field observation and stress that both approaches yielded basically identical results.

We found a pronounced hierarchy in size and competitive abilities among the four species. Although the sowing pattern could not reverse this hierarchy because Stellaria was so much larger than the other species, spatial aggregation was effective in changing the performance of the species. By changing the frequency of encounters between smaller and larger individuals, spatial aggregation enabled competitively intermediate species to resist superior ones, to grow better and, at least in Capsella, to reach the size of reproduction more often than if they were randomly distributed.

The dry-mass differences between sowing patterns in Capsella and Poa monocultures (for Capsella only at high density) were unexpected. Thus, aggregation might be important regardless of neighbor identity and intraspecific variation in competitive ability within pure stands might result in effects similar to those with interspecific variation. We could not find an explanation for this effect but we think it is worth mentioning because it was relatively large. However, we emphasize that the differences were not significant and that the results did not change qualitatively if monocultures were excluded from the analyses. Therefore, we regard the positive effect of aggregation on Capsella and Poa primarily as a result of interspecific interactions, also because differences among species were so much larger than variation within species.

We are well aware that our experiment must be considered as a preliminary sketch of the potential effects of intraspecific aggregation and that extrapolation to field conditions is at best risky. Natural communities are much more species rich and generally more variable, and species interact over much longer periods of time than in our experiment. However, it was the intention of this experiment to demonstrate that there is an aggregation effect per se, rather than to compare its importance with that of other factors. Therefore, the experiment should be regarded as a starting point for more intense, realistic, and comprehensive studies.

As we tested aggregation only at one particular spatial scale $(5 \mathrm{~cm})$, it would be rewarding to study the patterns of aggregation on a wider range of scales with communities of larger plants to test how general our findings are. Moreover, we artificially created local aggregation on a homogeneous substrate, and thus ignored the various ways that nonrandom species distributions emerge under field conditions. Spatial variation in site conditions is well known for practically all communities; it might be difficult to disentangle in the field whether local aggregation or underlying heterogeneity in the site conditions contributes more to species coexistence. Additionally, local aggregation can also re- 
sult endogenously from life-history traits such as limited seed dispersal and clonal growth. It would therefore be particularly informative to perform a study over a longer period of time, allowing seed set and seedling emergence in the next generations and to test whether the communities starting from different spatial arrangements eventually converge to similar patterns of aggregation. Although we lack data on long-term effects, we showed that aggregation increases both the likelihood to flower and the reproductive biomass of Capsella. Thus, we think it is safe to assume that local aggregation can maintain this species also in the following generations. Furthermore, an interaction between exogenous and endogenous causes of local aggregation also leaves open the possibility that a patchy distribution of resources is the consequence rather than the cause of high species diversity.

Although our experiment is limited in weighing the relative importance of intraspecific aggregation over other influences, it clearly demonstrates the effect as such and without potentially confounding effects. Furthermore, we regard it as a rather conservative demonstration of the effect of spatial aggregation because it ran under ideal conditions for plant growth (homogenized and nutrient-rich garden soil, regular watering) in which light becomes the only limiting resource (Tilman 1999). We expect an even stronger promotion of species diversity due to intraspecific aggregation when plants compete for more than just one resource.

A final but speculative implication from "spatial theory" is that local aggregation often represents a spatial genetic structure, so that neighboring individuals not only belong to the same species as in our experiment but are genetically related with each other (Cheplick 1992, Kalisz et al. 1999). Similar to clonal growth, limited seed dispersal can create neighborhoods whose individuals are related, which implies that limited seed dispersal could be part of an evolved strategy to cope with pressure of competitors. The consequences of genetic substructuring for species coexistence are poorly understood and merit further investigations.

In conclusion, we have presented experimental evidence that details of the spatial arrangement of plants in a community can profoundly influence their competitive interactions. Intraspecific aggregation can promote species coexistence by retarding competitive exclusion. Together with the rich body of theoretical models on spatial ecology and observational data, experimental studies such as ours add important insights for a general and mechanistic understanding of the forces structuring plant communities and the factors maintaining biodiversity in natural habitats.

\section{ACKNOWLEDGMENTS}

We thank M. Zimmermann and S. Amsler for much-appreciated logistic support and D.M. Newbery, H. Auge, E. Sayer, M. Schädler, S. Wilson, and two anonymous reviewers for comments on earlier drafts of the manuscript.

\section{Literature Cited}

Bergelson, J. 1990. Life after death: site pre-emption by the remains of Poa annua. Ecology 71:2157-2165.

Bolker, B. M., and S. W. Pacala. 1999. Spatial moment equations for plant competition: understanding spatial strategies and the advantages of short dispersal. American Naturalist 153:575-602.

Cheplick, G. P. 1992. Sibling competition in plants. Journal of Ecology 80:567-575.

Czárán, T., and S. Bartha. 1992. Spatiotemporal dynamic models of plant populations and communities. Trends in Ecology and Evolution 7:38-42.

Dieckmann, U., R. Law, and J. A. J. Metz, editors. 2000. The geometry of ecological interactions: simplifying spatial complexity. Cambridge University Press, Cambridge, UK.

Durrett, R., and S. A. Levin. 1994. Stochastic spatial models: a user's guide to ecological applications. Philosophical Transactions of the Royal Society of London B 343:329350.

Garrett, K. A., and P. M. Dixon. 1998. When does the spatial pattern of weeds matter? Predictions from neighborhood models. Ecological Applications 8:1250-1259.

Goldberg, D. E., and A. M. Barton. 1992. Patterns and consequences of interspecific competition in natural communities: a review of field experiments with plants. American Naturalist 139:771-801.

Gurevitch, J., L. Morrow, A. Wallace, and J. S. Walsh. 1992. A meta-analysis of competition in field experiments. American Naturalist 140:539-572.

Harper, J. L. 1977. The population biology of plants. Academic Press, London, UK.

Hassell, M. P., H. N. Comins, and R. M. May. 1994. Species coexistence and self-organizing spatial dynamics. Nature 370:290-292.

Horn, H. S., and R. H. MacArthur. 1972. Competition among fugitive species in a harlequin environment. Ecology 53: 749-752.

Kalisz, S. F., M. Hanzawa, S. J. Tonsor, D. A. Thiede, and S. Voigt. 1999. Ant-mediated seed dispersal alters pattern of relatedness in a population of Trillium grandiflorum. Ecology 80:2620-2634.

Kareiva, P. 1990. Population dynamics in spatially complex environments: theory and data. Philosophical Transaction of the Royal Society of London B 330:175-190.

Pacala, S. W. 1997. Dynamics of plant communities. Pages 532-555 in M. J. Crawley, editor. Plant ecology. Blackwell Scientific, Oxford, UK.

Pacala, S. W., and D. H. Deutschman. 1995. Details that matter: the spatial distribution of individual trees maintains forest ecosystem function. Oikos 74:357-365.

Payne, R. W., P. W. Lane, A. E. Ainsley, K. E. Bicknell, P. G. N. Digby, P. Harding, K. Leech, H. R. Simpson, A. D. Todd, P. J. Verrier, and R. P. White. 1987. GENSTAT 5 reference manual. Clarendon Press, Oxford, UK.

Rees, M., P. J. Grubb, and D. Kelly. 1996. Quantifying the impact of competition and spatial heterogeneity on the structure and dynamics of a four-species guild of winter annuals. American Naturalist 147:1-32.

Ross, M. A., and J. L. Harper. 1972. Occupation of biological space during seedling establishment. Journal of Ecology 60:77-88.

Schmid, B., and J. L. Harper. 1985. Clonal growth in grassland perennials. I. Density and pattern-dependent competition between plants with different growth forms. Journal of Ecology 73:793-808. 
Shmida, A., and S. Ellner. 1984. Coexistence of plant species with similar niches. Vegetatio 58:29-55.

Silvertown, J., S. Holtier, J. Johnson, and P. Dale. 1992. Cellular automaton models of interspecific competition for space - the effect of pattern on process. Journal of Ecology 80:527-534.

Stoll, P., and J. Weiner. 2000. A neighborhood view of in teractions among plants. Pages 11-27 in U. Dieckmann, R. Law, and J. A. J. Metz, editors. The geometry of ecological interactions: simplifying spatial complexity. Cambridge University Press, Cambridge, UK.

Tilman, D. 1994. Competition and biodiversity in spatially structured habitats. Ecology 75:2-16.
Tilman, D. 1999. The ecological consequences of changes in biodiversity: a search for general principles. Ecology 80: $1455-1474$.

Tilman, D., and P. Kareiva, editors. 1997. Spatial ecology: the role of space in population dynamics and interspecific interactions. Princeton University Press, Princeton, New Jersey, USA.

Weiner, J., and P. T. Conte. 1981. Dispersal and neighborhood effects in an annual plant competition model. Ecological Modelling 13:131-147.

Wilson, W. G., and R. M. Nisbet. 1997. Cooperation and competition along smooth environmental gradients. Ecology 78:2004-2017. 